\title{
The determinants of life satisfaction in Serbia: Findings from the Gallup World Poll
}

\author{
Veljko Jovanović · Mohsen Joshanloo
}

\begin{abstract}
Research on life satisfaction in non-Western countries has grown somewhat in recent years, but still lags far behind that of developed countries. The present study was aimed at investigating determinants of life satisfaction in Serbia, a developing country that has experienced a number of difficulties over the past three decades. A large, representative Serbian sample (a total of 11,618 participants; $54.6 \%$ females, Mage $=47.02$ ) from the Gallup World Poll was used. The results showed substantial gender differences in life satisfaction only among the oldest old (aged 81-99), with elderly women reporting substantially lower life satisfaction than elderly men (Cohen's $d=0.38$ ). Life satisfaction showed a steady, progressive decline among women, whereas men's life satisfaction declined until approximately 50 years of age, and then remained relatively stable. The relationship between income and life satisfaction was positive, but much stronger at lower income levels. Robust predictors of life satisfaction in both men and women and across age groups were satisfaction with standard of living and household income, negative affect, and social support.
\end{abstract}

Keywords: life satisfaction, Serbia, age, gender, Gallup World Poll

\section{Introduction}

Subjective wellbeing (SWB) has become one of the most lively and rapidly developing research areas in the field of social sciences over the past three decades. SWB is typically defined in terms of two components that capture an individual's subjective evaluations about life: cognitive (i.e., life satisfaction) and affective (positive affect and negative affect) (Diener \& Ryan, 2009). A great deal of research has been devoted to the understanding of the nature of SWB (Busseri \& Sadava, 2011), its predictors (Galinha \& Pais-Ribeiro, 2011), and its potential benefits (De Neve, Diener, Tay, \& Xuereb, 2013; Diener \& Chan, 2011). Moreover, many leading authors in the field have debated the importance of SWB for public policy decisions and its value as a measure of social progress (e.g., Dolan \& Metcalfe, 2012; Easterlin, 2013; Oishi \& Diener, 2014).

Although increasing attention has been paid to investigating SWB across different cultural contexts (Tov \& Diener, 2007), the vast majority of studies on predictors of life satisfaction have been conducted on WEIRD (Western, Educated, Industrialized, Rich, Democratic; Henrich, Heine, \& Norenzayan, 2010) samples. On the other hand, detailed research on wellbeing in developing countries still lags behind research in developed and English-speaking countries. The present study is the first to use the large data set from the Gallup World Poll (GWP) to investigate predictors of SWB in Serbia.

There may be many important reasons for wellbeing researchers to study life satisfaction in under-researched countries. Most conclusions about life satisfaction, and wellbeing generally, 
have been based on the findings in Western countries, and are usually assumed to hold true for people in most, if not all countries (e.g., Lomas, 2015). This universalist perspective fails to recognize that determinants of wellbeing may have different importance for people across different countries, which might also lead to different policy implications. To help us understand whether factors found to be important for life satisfaction in Western countries are universally applicable across cultures, research comprising individuals from different socioeconomic background needs to be executed.

\subsection{Subjective wellbeing in Serbia}

Serbia is a developing country located in southeast Europe's Balkan peninsula, with a population of approximately 7 million people, and it was a part of the Federal Republic of Yugoslavia until its breakup in 1991. Given the turbulence of the past few decades (e.g., the war in former Yugoslavia between 1991 and 1995, sanctions during the 1990s, hyperinflation, the NATO bombing in 1999, the overthrow of the Milošević regime in 2000, etc.), the issue of Serbians' quality of life and wellbeing deserves careful inspection. A rough sketch of SWB in Serbia over the past decade can be drawn from reports that use data from large-scale, international studies of wellbeing and quality of life. These studies have consistently shown that levels of SWB and quality of life in Serbia are among the lowest in Europe. For example, the European Quality of Life Survey 2012 (Eurofound, 2012) conducted in 34 European countries found that Serbia ranked 28th in life satisfaction, with the inhabitants of Serbia rating their life satisfaction at 6.3 on average (on a scale from 1 to 10), compared with an average of 7.1 found in EU countries. Similar results have been reported in the most recent edition of the World Happiness Report (Helliwell, Layard, \& Sachs, 2018), with an average life satisfaction in Serbia of 5.398 (on a scale from 0 to 10) during the period 2015-2017. This ranks Serbia 78th out of the 156 countries included in the report, with average life satisfaction similar to the other countries of the former Yugoslavia (Bosnia and Herzegovina, Croatia, Macedonia, Montenegro, and Slovenia) but well below developed European countries such as Norway and Austria. According to the Gallup-Healthways Global Well-Being Index for 2014 (Gallup, 2015), only $15.3 \%$ people in Serbia are thriving in three or more wellbeing elements (purpose, social, financial, community, and physical), which is below the global average of $17 \%$.

Despite discouraging results about the levels of wellbeing among those living in Serbia, there is a lack of studies aimed at trying to explain these findings. However, due to poor socioeconomic and political conditions in Serbia over the past few decades, relatively low levels of wellbeing are not surprising. For example, the state of the economy in Serbia is characterized by frequent recessions, a high unemployment rate (especially among youth), high levels of poverty (The World Bank Group, 2015), and high income inequality (Krstić, 2016). In addition, institutional corruption in Serbia is widespread (CLDS, 2014), the quality of the health system is among the worst in Europe (Health Consumer Powerhouse, 2016), human rights violations are pervasive (Belgrade Centre for Human Rights, 2017), and the level of social capital is rather low (Legatum Institute, 2017). Despite these adverse conditions, no study to date has examined the associations between socio-economic conditions and SWB in Serbia using representative samples. 


\subsection{Predictors of life satisfaction}

Research into predictors of SWB has revealed a complex network of socio-demographic, political, economic, cultural, interpersonal, and intrapersonal factors associated with life satisfaction. Most pioneering studies have been interested in external and situational factors influencing life satisfaction and they have come to the surprising conclusion that sociodemographic variables (e.g., age, education, marital status, income) have only a limited predictive value for explaining an individual's life satisfaction (Veenhoven, 2015). However, the conclusions about the small effects of objective living conditions on life satisfaction have probably been misinterpreted. As Lucas and Diener (2015) argue, "[T] he very fact that we can come up with a large list of such intuitively appealing predictors means that the size of any one of those effects likely will be small. As should be obvious, the more predictors there are of a single criterion, the smaller the association between any one predictor and that criterion can be" (p. 585). This implies that a thorough investigation of life satisfaction determinants needs to include a broad range of socio-demographic variables, since many of them, despite small statistical effects, have a meaningful contribution to an understanding of life satisfaction.

As previously noted, most wellbeing studies take a universalist stance, assuming that predictors of life satisfaction may be context-free. However, it has been found that the significance of many specific predictors of SWB varies across cultures, i.e., that the relationship between SWB and both internal and external factors is often moderated by socio-cultural context. For example, income has been shown to play an important role in determining SWB in both within-country and between-country analyses (Sacks, Stevenson, \& Wolfers, 2012), but the relationship between economic status and SWB has been found to be stronger among poorer countries (Howell \& Howell, 2008; but see Sacks et al., 2012 for a different view). Similarly, religiosity has been found to be associated with higher SWB (Stavrova, Fetchenhauer, \& Schlösser, 2013), but this appears to be true only for countries experiencing adverse socioeconomic conditions, whereas in countries with favorable circumstances, religiosity and SWB are not correlated (Diener, Tay, \& Myers, 2011). Recently, Ng and Diener (2014) have revealed that the relationships between SWB and both financial satisfaction and post-materialist needs (autonomy, respect, social support) were stronger in affluent nations than in poorer ones.

Previous studies have also indicated a complex relationship between age and SWB across different countries. Although most studies have found a U-shaped relationship between life satisfaction and age, with the lowest levels of life satisfaction in middle adulthood (Cheng, Powdthavee, \& Oswald, 2017), this does not hold for all regions of the world. For example, a steady decline of life satisfaction with age has been reported for individuals from Eastern Europe, the former Soviet Union, and Latin America (Steptoe, Deaton, \& Stone, 2015). Furthermore, the results regarding the relationships between socio-demographic variables and SWB have often been inconsistent, and probably the best example of this inconsistency is research on gender differences in SWB (for a detailed review, see Batz \& Tay, 2018). To sum up, these studies highlight the importance of understanding SWB in relation to the socio-cultural context, and emphasize the need to examine the factors associated with SWB across different nations or cultures, since the results obtained in a single country cannot be generalized to other countries.

\subsection{The present study}

To date, no research on life satisfaction in Serbia has been conducted using representative samples, and the determinants of life satisfaction in Serbia remain largely unknown. The 
limited number of research findings about SWB in Serbia limits comparability with the results of research conducted in other countries. This also hinders the development of a debate about the policy implications of research on wellbeing in Serbia, as there is no solid empirical base about the state of wellbeing among Serbian inhabitants.

The main goal of the present study was to examine predictors of life satisfaction using large, representative Serbian samples from the GWP. We investigated: (a) age and gender differences in life satisfaction; and (b) the predictive value of socio-demographic variables, domain satisfactions, needs satisfaction, affective wellbeing (positive and negative affect) and some indicators of social capital in predicting life satisfaction. Given the lack of research on life satisfaction in Serbia, our expectations have been derived from previous cross-cultural studies that included countries with a similar socio-economic background to Serbia. First, in accordance with previous findings which have shown that positive affect, income, and social support are robust predictors of life satisfaction across different cultures (for a review, see Diener, Lucas, \& Oishi, 2018), we expected these well-known predictors to be positively associated with life satisfaction in Serbia. Second, similar to findings in other post-communist countries (e.g., Steptoe et al., 2015), we expected that life satisfaction would decline with age. Third, as previous studies have demonstrated that the positive associations between indicators of social capital and life satisfaction were weaker in low- and middle-income countries than in rich countries (Calvo, Zheng, Kumar, Olgiati, \& Berkman, 2012), we hypothesized that social capital indicators included in the present study would have significant, but weak association with life satisfaction in Serbia. Finally, socio-demographic variables (except age and income) were expected to yield weak or non-significant associations with life satisfaction (e.g., Diener, Suh, Lucas, \& Smith, 1999). To evaluate whether there were gender and age differences in the predictors of life satisfaction, separate analyses were conducted for men and women, and for different age groups.

\section{Method}

\subsection{Participants}

The data were from the Gallup World Poll (GWP), which has collected nationally representative samples from Serbia since 2007. Each year, participants (aged 15 and older) have been contacted via landline and/or mobile telephones for participation in the survey. Sample sizes are about 1,000 for each year, except for the year 2007, with a sample of 1,556. We used all available data from 2007 to 2017 in the present analyses, consisting of 11,618 participants ( $54.6 \%$ females, $M_{\text {age }}=47.02, S D_{\text {age }}=17.38$ ). The age distribution is shown in Figure 1 below. 


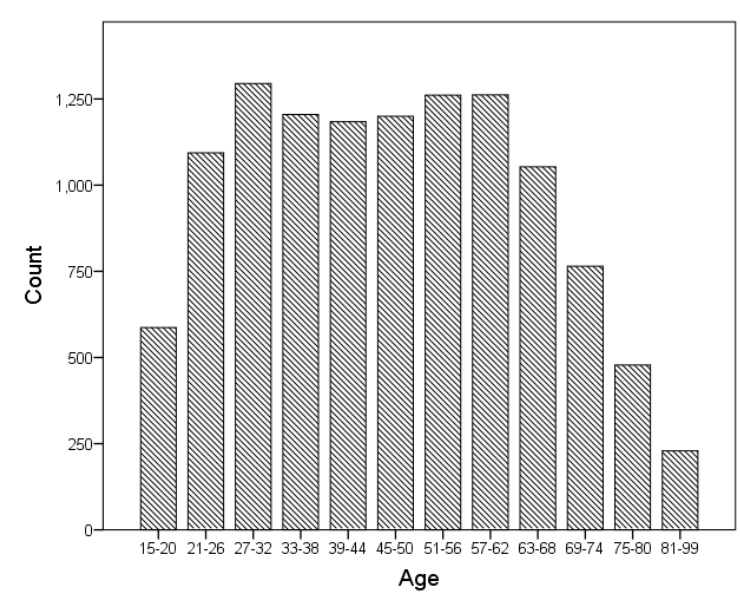

Figure 1. Age distribution

\subsection{Measures}

We used several items from the collection of Gallup World Poll items. These items measure variables that are generally identified in the literature as relevant predictors of SWB. The items and their response formats are presented in the Supplementary Material (see Table A). Included was the Cantril Ladder of Life Scale (Cantril, 1965) to measure life satisfaction, which is the main outcome of the present study.

Given that the intercorrelations between the items were weak, all of the items were used separately as variables. However, we were able to calculate and use three composite variables, based on the results of separate reliability and factor analyses. The results of a principal axis factoring showed that stress, worry, sadness, and anger formed a single factor (Eigenvalue $=$ 2.02 , variance explained $=50.37 \%)$, with factor loadings ranging from .52 to .61 $(\alpha=.67)$. Laughter and enjoyment formed a single factor (Eigenvalue $=1.45$, variance explained $=$ $72.49 \%)$, with factor loadings of $.67(\alpha=.62)$. Finally, perceptions of corruption in businesses and the government also formed a single factor (Eigenvalue $=1.60$, variance explained $=$ $80.11 \%)$, with factor loadings of $.77(\alpha=.75)$.

\section{Results}

\subsection{Life satisfaction by age and gender}

The results showed that there was no substantial gender difference in life satisfaction (Cohen's $d=0.00$; for both males and females $M=4.95, S D=2.21$ ). Figure 2 below shows the distribution of life satisfaction by age and gender. Locally Weighted Smoothing (LOESS) was used in the scatter graphs for a more accurate representation of the data. The graph shows that life satisfaction declines with age in Serbia. A steady progressive decline of life satisfaction is evident among women, whereas men's life satisfaction shows a steady decline until approximately 50 years of age, and remains relatively stable afterwards. A detailed inspection of gender differences in life satisfaction across age (see Table B in the Supplementary Material) indicated that the largest differences were found among the oldest old (aged 81-99), with elderly women reporting substantially lower life satisfaction than elderly men (Cohen's $d=$ $0.38)$. 


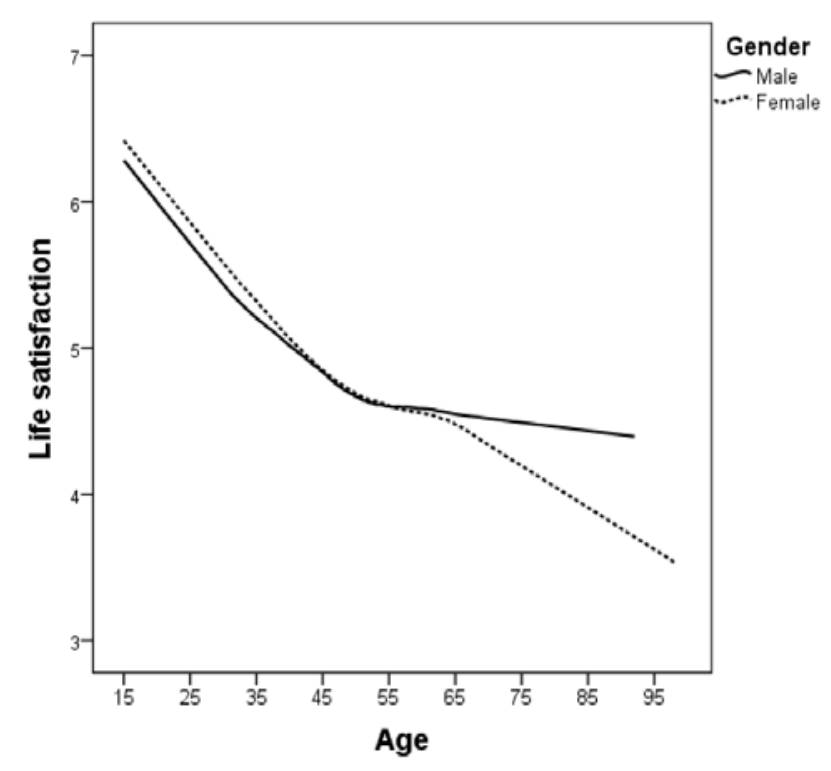

Figure 2. Life satisfaction by age and gender

As a supplementary analysis, we also looked at gender differences in affect. The results showed that women reported higher negative affect than men, but a small effect size was found (Cohen's $\left.d=0.13 ; M_{\text {females }}=0.36, S D_{\text {females }}=0.33, M_{\text {males }}=0.32, S D_{\text {males }}=0.32\right)$. No gender difference was found in positive affect (Cohen's $d=0.01 ; M_{\text {females }}=0.49, S D_{\text {females }}=0.43, M_{\text {males }}=0.49, S D_{\text {males }}$ $=0.42$ ).

\subsection{Explaining gender differences in life satisfaction across age}

In an attempt to explain the gender patterns observed in life satisfaction in Serbia, we looked at the distributions of some of the predictors of wellbeing across age and gender. Figure 3 below shows the distributions of six variables, which partially explains why life satisfaction is lower in women than men at advanced ages. Over the age of 50, women are less educated than men, and are less satisfied with their standard of living and household income than men. They also experience more worry, sadness, and health problems than men at advanced ages. 

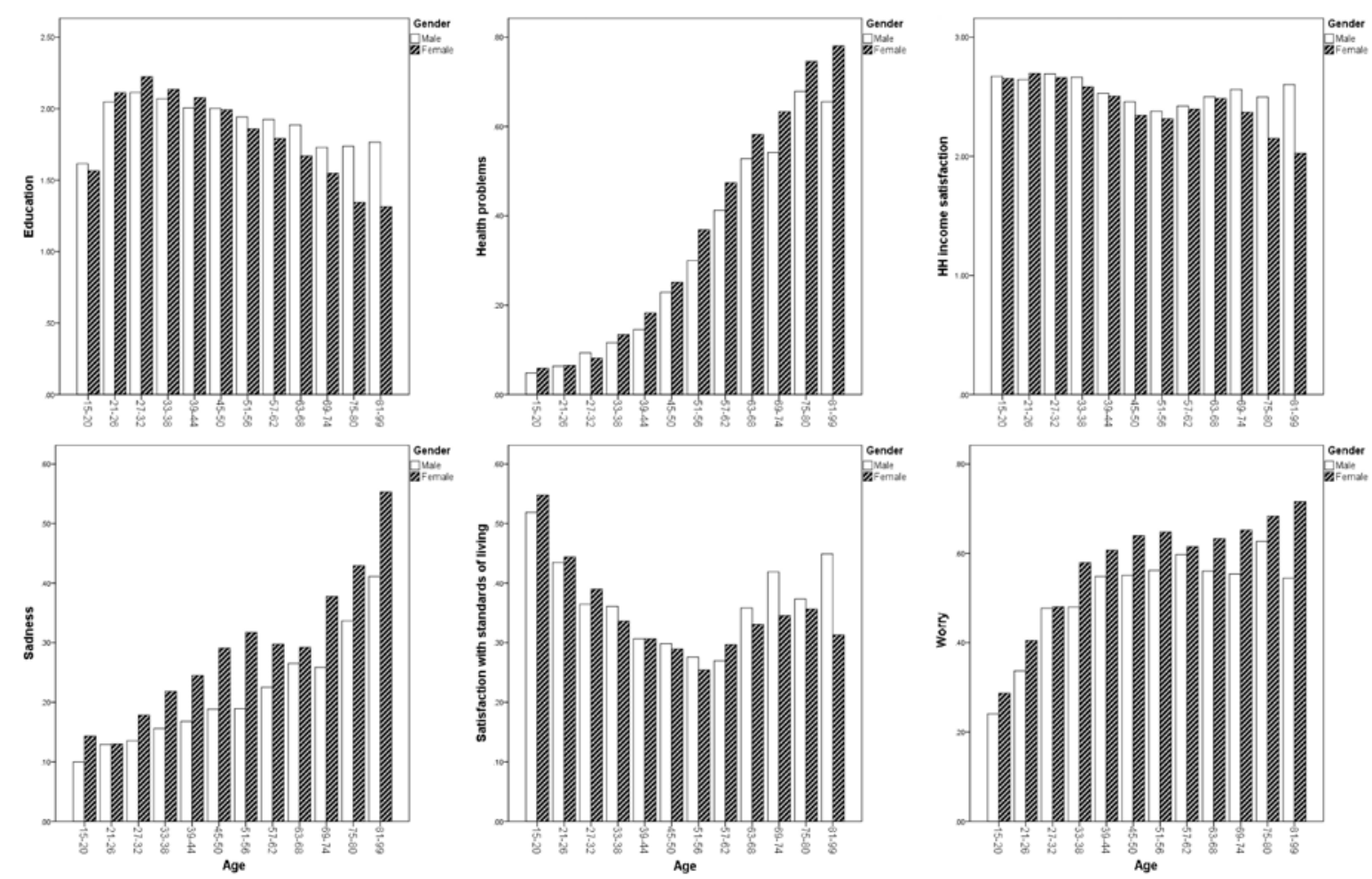

Figure 3. Age and gender patterns in the predictors of life satisfaction

\subsection{Demographic predictors of life satisfaction}

In addition to the analysis of age and gender, we also examined the contribution of other important demographic variables. Table 1 presents the results of seven separate ANOVAs, using demographic variables as independent variables explaining life satisfaction. For religious affiliation, several categories with very small sample sizes (e.g., "Hinduism" and "atheist") were combined with the "other" category. The strongest predictor of life satisfaction was income quintiles (explaining $7.2 \%$ of the variance), followed by education (explaining $4.9 \%$ of the variance), and relationship status (explaining 3.9\% of the variance). As shown in Table 1 (see also Figure A in the Supplementary Material), low-income, less educated, and divorced and widowed individuals were less satisfied than high-income, more educated, and individuals with other relationship statuses.

Table 1. ANOVA results predicting life satisfaction

\begin{tabular}{llccc}
\hline & & $M$ & $S D$ & $N$ \\
\hline Employment & Employed full time for an employer & 5.51 & 2.00 & 2696 \\
$d f=5,8002$ & Employed full time for self & 4.86 & 2.32 & 604 \\
$F=36.15$ & Employed part time, do not want full time & 5.34 & 2.22 & 354 \\
$p<.001$ & Unemployed & 4.42 & 2.34 & 271 \\
partial $\eta^{2}=.022$ & Employed part time, want full time & 4.87 & 2.21 & 374 \\
& Out of workforce & 4.85 & 2.32 & 3709 \\
& Total & 5.08 & 2.25 & 8008 \\
\hline Education & Elementary & 4.17 & 2.29 & 2370 \\
$d f=2,10537$ & Secondary & 5.04 & 2.12 & 6610 \\
$F=268.98$ & Tertiary (four years beyond high school) & 5.76 & 2.09 & 1560 \\
$p<.001$ & Total & 4.95 & 2.21 & 10540 \\
partial $\eta^{2}=.049$ & & & & \\
\hline
\end{tabular}




\begin{tabular}{|c|c|c|c|c|}
\hline \multirow{5}{*}{$\begin{array}{l}\text { Location } \\
\qquad \begin{array}{l}d f=3,10475 \\
F=53.97 \\
p<.001 \\
\text { partial } \eta^{2}=.015\end{array}\end{array}$} & Rural or farm & 4.60 & 2.24 & 3163 \\
\hline & Small town or village & 4.95 & 2.20 & 3605 \\
\hline & Large city & 5.30 & 2.14 & 3219 \\
\hline & Suburb of a large city & 4.90 & 2.25 & 492 \\
\hline & Total & 4.95 & 2.21 & 10479 \\
\hline \multirow{4}{*}{$\begin{array}{l}\text { Religious affiliation } \\
\begin{array}{l}d f=2,9011 \\
F=1.74 \\
p=.175 \\
\text { partial } \eta^{2}=.000\end{array}\end{array}$} & Christian & 4.99 & 2.23 & 8330 \\
\hline & Muslim & 4.99 & 2.13 & 375 \\
\hline & Other & 5.24 & 2.36 & 309 \\
\hline & Total & 5.00 & 2.24 & 9014 \\
\hline \multirow{7}{*}{$\begin{array}{l}\text { Relationship status } \\
\qquad \begin{array}{l}d f=5,10431 \\
F=85.56 \\
p<.001 \\
\text { partial } \eta^{2}=.039\end{array}\end{array}$} & Single & 5.59 & 2.12 & 2530 \\
\hline & Married & 4.90 & 2.14 & 5731 \\
\hline & Separated & 4.61 & 2.22 & 249 \\
\hline & Divorced & 4.26 & 2.47 & 436 \\
\hline & Widow & 4.22 & 2.24 & 1322 \\
\hline & Domestic & 5.10 & 2.35 & 169 \\
\hline & Total & 4.95 & 2.21 & 10437 \\
\hline \multirow{6}{*}{$\begin{array}{l}\text { Income quintiles } \\
\begin{array}{l}d f=4,9009 \\
F=175.12 \\
p<.001 \\
\text { partial } \eta^{2}=.072\end{array}\end{array}$} & 1 Poorest $20 \%$ & 4.08 & 2.27 & 1565 \\
\hline & 2 Second $20 \%$ & 4.57 & 2.21 & 1733 \\
\hline & 3 Middle $20 \%$ & 5.01 & 2.17 & 1749 \\
\hline & 4 Fourth $20 \%$ & 5.24 & 2.11 & 1881 \\
\hline & 5 Richest $20 \%$ & 5.84 & 2.04 & 2086 \\
\hline & Total & 5.00 & 2.24 & 9014 \\
\hline \multirow{4}{*}{$\begin{array}{l}\text { Country of birth } \\
\begin{array}{l}d f=1,8991 \\
F=0.01 \\
p=.936 \\
\text { partial } \eta^{2}=.000\end{array}\end{array}$} & Born in Serbia & 5.00 & 2.23 & 8176 \\
\hline & Born in another country & 5.00 & 2.33 & 817 \\
\hline & Total & 5.00 & 2.24 & 8993 \\
\hline & & & & \\
\hline
\end{tabular}

Employment status explained $2.2 \%$ of the variance, with individuals who were employed full time for an employer and those who were employed part time with no intention to have a fulltime job being the most satisfied. Location explained $1.5 \%$ of the variance, with people living in large cities being more satisfied than those living in other locations. Religious affiliation and country of birth were not significant predictors. An overall ANOVA including all of the seven variables showed that the variables collectively explained about $12.5 \%$ of the variance in life satisfaction. When entered alongside each other, the unique contributions of the variables were reduced to $.5 \%, .9 \%, .1 \%, 0 \%, 3.3 \%, 4.3 \%, 0 \%$ for employment, education, location, religious affiliation, relationship status, income quintile, and birth country, respectively.

\subsection{Regression analysis}

We used all of the predictors of life satisfaction, along with important demographic variables, in a multiple regression analysis, using the enter method. A total sample of 5,738 participants had no missing values on all of the 28 variables and were included in the analysis. The results are shown in Table 2 below. 
Table 2. Results of regression analysis

\begin{tabular}{|c|c|c|c|c|c|c|}
\hline & $\mathrm{B}$ & $95 \%$ CI for B & $t$ & $p$ & $\beta$ & $r_{\mathrm{sp}}$ \\
\hline (Constant) & 2.45 & $(2.16,2.79)$ & 15.36 & .000 & - & - \\
\hline Female & 0.07 & $(-.03, .17)$ & 1.34 & .180 & .02 & .01 \\
\hline Age & -0.02 & $(-.02,-.01)$ & -9.43 & .000 & -.13 & -.10 \\
\hline Age squared & 0.00 & $(.00, .00)$ & 1.31 & .191 & .02 & .01 \\
\hline Negative affect & -0.78 & $(-.96,-.61)$ & -8.87 & .000 & -.11 & -.09 \\
\hline Positive affect & 0.49 & $(.35, .64)$ & 6.86 & .000 & .09 & .07 \\
\hline Health problems & -0.28 & $(-.40,-.16)$ & -4.43 & .000 & -.06 & -.05 \\
\hline $\mathrm{HH}$ income satisfaction & 0.51 & $(.45, .57)$ & 15.74 & .000 & .20 & .17 \\
\hline Satisfied with standard of living & 0.88 & $(.77,1.00)$ & 14.76 & .000 & .19 & .15 \\
\hline Satisfied with healthcare & 0.14 & $(.04, .25)$ & 2.68 & .007 & .03 & .03 \\
\hline Satisfied with housing & 0.07 & $(-.04, .17)$ & 1.24 & .214 & .01 & .01 \\
\hline Confidence in government & -0.11 & $(-.22,-.00)$ & -1.99 & .047 & -.02 & -.02 \\
\hline Corruption & -0.06 & $(-.20, .07)$ & -0.93 & .351 & -.01 & -.01 \\
\hline City satisfaction & 0.25 & $(.14, .36)$ & 4.40 & .000 & .05 & .05 \\
\hline Helped & 0.06 & $(-.05, .17)$ & 1.03 & .305 & .01 & .01 \\
\hline Volunteered & 0.14 & $(-.08, .35)$ & 1.25 & .213 & .01 & .01 \\
\hline Donated & 0.21 & $(.09, .32)$ & 3.56 & .000 & .04 & .04 \\
\hline Religion important & 0.07 & $(-.03, .17)$ & 1.44 & .149 & .02 & .02 \\
\hline Social support & 0.59 & $(.46, .73)$ & 8.85 & .000 & .10 & .09 \\
\hline Mastery & 0.09 & $(-.02, .20)$ & 1.61 & .107 & .02 & .02 \\
\hline Freedom & 0.16 & $(.05, .26)$ & 2.88 & .004 & .034 & .03 \\
\hline Safe at night & 0.08 & $(-.03, .19)$ & 1.41 & .159 & .016 & .02 \\
\hline Respect & 0.00 & $(-.13, .14)$ & 0.02 & .985 & .000 & .00 \\
\hline Education & 0.14 & $(.05, .23)$ & 3.08 & .002 & .037 & .03 \\
\hline Unemployed & -0.50 & $(-.75,-.24)$ & -3.79 & .000 & -.040 & -.04 \\
\hline Large city & -0.03 & $(-.13, .08)$ & -0.48 & .632 & -.005 & -.01 \\
\hline Widow & -0.10 & $(-.26, .07)$ & -1.18 & .239 & -.015 & -.01 \\
\hline Divorced & -0.09 & $(-.32, .14)$ & -0.78 & .434 & -.008 & -.01 \\
\hline
\end{tabular}

Note: $\mathrm{HH}=$ household income, $\mathrm{CI}=$ confidence interval, $r_{\mathrm{sp}}=$ semipartial correlation

The predictors collectively explained about $37.5 \%$ of the variance in life satisfaction, $F(27,5710)$ $=127.01, p<.001, R^{2}=.375$. Thirteen out of 27 variables were not significant predictors of life satisfaction at the .05 level. Based on the results of a separate stepwise regression analysis, household income satisfaction was the strongest predictor, explaining about $20.8 \%$ of the variance. The second strongest predictor was satisfaction with standard of living, contributing an additional $6.1 \%$. Age, negative affect, positive affect, and social support came next, explaining $4.1 \%, 2.5 \%, 1.2 \%$, and $1.1 \%$, respectively. These six variables jointly explained $36 \%$ of the variance in life satisfaction scores. The other variables collectively added about $1.5 \%$ of additional variance. Based on the results of the stepwise regression, gender, squared age, satisfaction with housing, confidence in the government, perceptions of corruption, helping behavior, volunteering, religiosity, mastery, feeling safe at night, feeling respected, living in a large city, and being a widow or divorced did not contribute significantly over and above other variables and were therefore excluded from the equation.

We also conducted regression analyses separately across age and gender groups, using the enter procedure, the results of which are shown in Tables 3 and 4 below. 
Table 3. Unstandardized regression coefficients for age and gender groups

(Constant)

Female

Age

Age squared

Negative affect

Positive affect

Health problems

$\mathrm{HH}$ income satisfaction

Satisfied with standard of living

Satisfied with healthcare

Satisfied with housing

Confidence in government

Corruption

City satisfaction

Helped

Volunteered

Donated

Religion important

Social support

Mastery

Freedom

Safe at night

Respect

Education

Unemployed

Large city

Widow

Divorced

\begin{tabular}{cc}
\multicolumn{2}{c}{ Gender } \\
\hline Male & Female \\
\hline $2.60^{* * *}$ & $2.47^{* * *}$
\end{tabular}

\begin{tabular}{cccc}
\multicolumn{4}{c}{ Age group } \\
\hline $15-24$ & $25-44$ & $45-64$ & $65+$ \\
\hline $4.01^{* * *}$ & $2.83^{* * *}$ & $1.95^{* * *}$ & $2.19^{* * *}$
\end{tabular}

$\begin{array}{llll}0.17 & 0.07 & -0.00 & 0.11\end{array}$

$-0.02^{* * *}-0.02^{* * *}$

$0.00 \quad 0.00$

$-0.69^{* * *}-0.86^{* * *}$

$0.50^{* * *} \quad 0.50^{* * *}$

$-0.30^{* *} \quad-0.26^{* *}$

$0.56^{* * *} \quad 0.47^{* * *}$

$0.87^{* * * *} \quad 0.89^{* * * *}$

$0.08 \quad 0.19^{* *}$

0.06

0.08

$-0.13$

$-0.09$

$-0.11$

$-0.03$

$0.26^{* *}$

$0.26^{* *}$

0.00

0.11

0.10

0.17

0.13

$0.26^{* *}$

0.07

0.08

$0.51^{* * *}$

$0.67^{* * * *}$

$0.26^{\text {** }}$

$-0.05$

0.12

$0.19^{* * *}$

0.02

0.11

$-0.03$

0.02

0.10

$0.18^{* *}$

$-0.55^{* *}$

$-0.46^{* *}$

0.01

$-0.06$

$-0.23$

$-0.05$

0.11

$-0.20$

$-$

$-0.75^{* *}$

0.22

$-0.69^{* * *}$

$0.39^{* *}$

$65^{* *}$

$0.56^{* * *}$

$-1.15^{\text {**** }}$

$-0.43$

$-0.25 \quad-0.34^{* * *}$

$0.82^{* * *}$

$0.37^{* * *}$

$0.41^{\text {**** }}$

$0.57^{* * *}$

$-0.16$

$1.19^{* * *}$

$0.90^{* * *}$

$0.83^{* * *}$

$0.62^{* * *}$

0.06

0.07

$0.25^{* *}$

$0.82^{* * *}$

$-0.06$

0.13

0.06

0.11

$-0.06$

$-0.13$

$-0.13$

0.03

$-0.20$

$-0.03$

$-0.17$

$-0.10$

0.27

$0.27^{* *}$

$0.34^{* *}$

0.04

0.06

0.02

0.04

0.00

$0.52^{*}$

0.10

$-0.29$

0.22

$0.33^{*}$

$0.20^{*}$

0.25 *

0.42

0.12

$-0.09$

0.16

0.00

$0.86^{\text {** }}$

$0.50^{* * * *}$

$0.69^{* * *}$

0.20

0.26

0.02

0.05

$0.47^{* *}$

0.06

$0.24 *$

0.14

0.26

0.14

0.02

0.07

0.09

$-0.01$

$0.24^{*}$

$-0.14$

0.13

$-0.33^{*}$

$0.20^{*}$

$0.32^{* * *}$

$-0.16$

$-0.61^{*}$

$-0.42^{*}$

$-0.57^{*}$

0.02

$-0.03$

$-0.09$

$-0.02$

0.13

$-1.08$

$-0.18$

$-0.14$

0.10

0.59

$-0.12$

Note: $\mathrm{HH}=$ household income.

${ }^{*} p<.05 ;{ }^{* *} p<.01 ;{ }^{* * *} p<.001$

Table 4 below also presents the five most important predictors for each group, based on separate regression analyses using the stepwise procedure for each group. We used four age categories, to represent emerging adulthood (15-24), young adulthood (25-44), middle adulthood (45-64), and late adulthood (65 and older). The age categorization was based on previous work by Steger, Oishi and Kashdan (2009), inspired by the classic works of Erikson (1968) and Arnett (2000). The results revealed that there were some slight differences in the predictors of life satisfaction across the age and gender groups, yet similarities are much more apparent than differences. 
Table 4. Regression results across age and gender groups

\begin{tabular}{ccccl}
\hline & $R^{2}$ & $F$ & $d f$ & Most important predictors \\
\hline $\begin{array}{c}\text { Gender } \\
\text { Male }\end{array}$ & .362 & 55.62 & 26,2554 & HH income, SWSL, age, PA, NA \\
$\begin{array}{c}\text { Female } \\
\text { Age group }\end{array}$ & .390 & 77.12 & 26,3130 & HH income, SWSL, age, PA, NA \\
$15-24$ & .370 & 13.15 & 25,559 & SWSL, HH income, social support, NA, mastery \\
$25-44$ & .295 & 32.38 & 25,1938 & SWSL, HH income, social support, NA, PA \\
$45-64$ & .356 & 43.57 & 25,1974 & SWSL, HH income, social support, NA, PA \\
$65+$ & .364 & 26.59 & 25,1163 & SWSL, HH income, social support, NA, PA \\
\hline
\end{tabular}

Note: The estimates come from regression analyses using the method of enter. The important predictors come from separate regression analyses using the stepwise method. SWSL = satisfaction with standard of living; $\mathrm{HH}$ income = satisfaction with household income; $\mathrm{PA}=$ positive affect; $\mathrm{NA}=$ negative affect.

\subsection{Relationship between household income and life satisfaction}

The relationship between per capita annual household income (in international dollars) and life satisfaction is shown in Figure 4. Incomes higher than $\$ 40,000$ are rare and not included in the graph. As can be seen, at extremely low levels of income, the relationship between income and life satisfaction is very strong. At higher levels of income, the relationship is still positive but it constantly becomes less steep with increasing income.

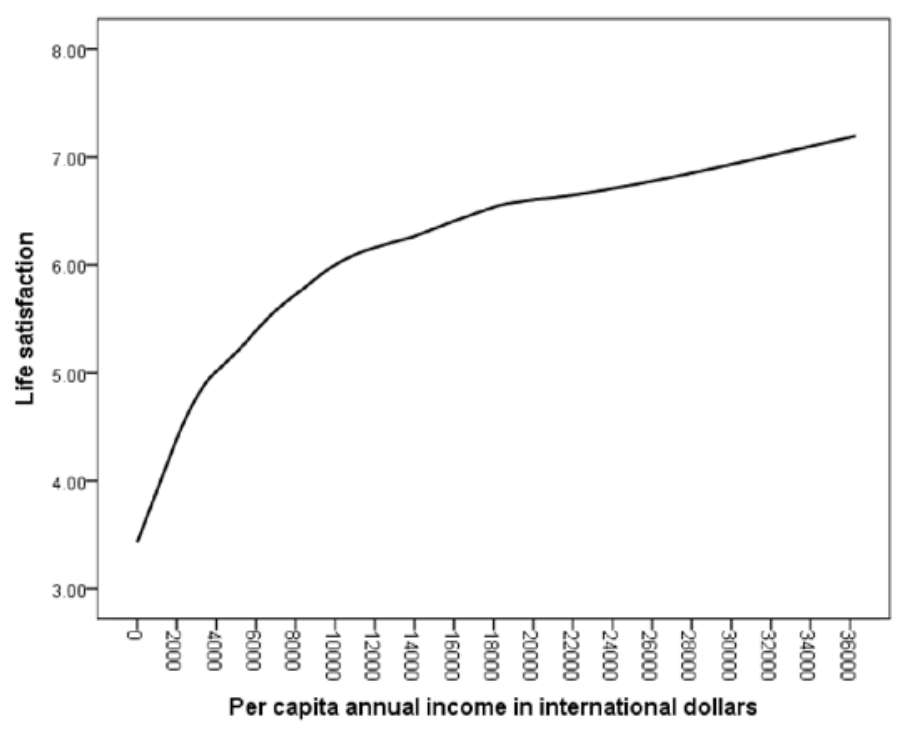

Figure 4. The relationship between annual household income (in international dollars) and life satisfaction in Serbia

\section{Discussion}

The main goal of the present study was to investigate the main predictors of life satisfaction in Serbia using representative samples from the Gallup World Poll (GWP) in the period from 2007 to 2017.

The results of the present study revealed no gender differences in life satisfaction when the analysis was conducted using the total sample. However, a more detailed inspection of the results, which took into consideration the participants' age, showed that this did not hold true in late adulthood. Gender differences in life satisfaction become evident in late adulthood 
among the oldest old, with elderly women reporting substantially lower life satisfaction then elderly men. A number of factors may explain gender differences in life satisfaction among the elderly, such as a greater number of health problems, higher levels of negative emotions, and lower satisfaction with income and standard of living among elderly women in comparison to elderly men. These results are in accordance with the explanations for gender differences in SWB offered by Batz and Tay (2018), who suggest that inequalities between men and women in access to educational, economic, and social resources might lead to lower life satisfaction among women who experience greater disadvantages in comparison to men. Findings from Serbia show that, indeed, women do have a lower rate of economic activity and a higher unemployment rate than men (Šobot, 2014), which probably has a detrimental effect on the fulfillment of women's needs, especially in their later years.

Findings regarding the relationship between age and life satisfaction in Serbia showed that men's life satisfaction decreased with age until middle adulthood and remained stable afterwards, whereas women's life satisfaction continued to decrease steadily with age. The well-established U-shaped relationship between age and life satisfaction found in previous cross-sectional studies (e.g., Blanchflower \& Oswald, 2008) was not evident in the Serbian data. However, our findings are in accordance with the results of studies showing that life satisfaction is U-shaped with age only in high-income and wealthy English-speaking countries, whereas many poor, middle-income, and post-communist countries show a progressive decline in life satisfaction with age (Deaton, 2008; Steptoe et al., 2015). It is no surprise that life satisfaction in Serbia does not increase after middle age, given that older people in Serbia face a number of adversities, such as poor social welfare and healthcare systems, a high poverty rate, and weak institutional support (Sevo et al., 2015; Rašević, 2010). In addition, elderly women in Serbia are poorer than men of the same age (Rašević, 2010), which might partially explain a greater decrease in life satisfaction among elderly females in the present study.

The findings regarding the relationship between household income and life satisfaction revealed a strong positive association at lower levels of income that remains positive but decreases at higher levels of household income. This is in line with previous findings (Frey \& Stutzer, 2002), and it supports the notion that once basic needs are met, further increase in income has only a limited effect on life satisfaction.

Among socio-demographic variables, when examined separately, income was the strongest predictor of life satisfaction, followed by education, relationship status, employment, and location. Lower life satisfaction was reported among low-income, less-educated, unemployed, widowed and divorced individuals, and individuals not living in large cities. Our results are in line with the findings of previous studies that examined associations between life satisfaction and income (Kahneman \& Deaton, 2010), education (Zhang, Braun, \& Wu, 2017), unemployment (Winkelmann, 2014), and marital status (Verbakel, 2012). Lower life satisfaction among individuals living in rural areas compared to urban areas is not surprising, given that rural areas in Serbia have much lower levels of quality of life (Beker et al., 2017), which is typical for poorer European countries (Shucksmith, Cameron, Merridew, \& Pichler, 2009).

When examined together, the socio-demographic variables explained a total of $12.5 \%$ variance in life satisfaction, with the largest unique contributions coming from income and relationship status. These findings are largely consistent with previous studies investigating the 
contribution of demographic variables to life satisfaction in developing countries (Camfield, 2012; Rukumnuaykit \& Pholphirul, 2016). As noted by Easterlin (2001), a positive association between happiness and income has been repeatedly found in representative national surveys, and this income-life satisfaction relationship has been one of the most robust findings in the field of wellbeing. The large significance of relationship status for life satisfaction can be explained by the high level of importance placed on the family in Serbia, which has traditionally been considered a collectivistic society (Hofstede, Hofstede, \& Minkov, 2010). Similar findings on the effects of marital status on life satisfaction have also been found in research on life satisfaction in collectivistic cultures, such as those found in Asia (Ngoo, Tey, \& Tan, 2015).

The analyses that, in addition to demographic variables, also included measures of domain satisfactions (e.g., satisfaction with household income, standard of living, healthcare, housing, place of residence), needs (e.g., social support, freedom, mastery, safety, respect), affective wellbeing, and indicators of social capital (e.g., confidence in the government, corruption, volunteering) revealed several robust predictors of life satisfaction across gender and age groups. Minor differences in predictors of life satisfaction were noted among men and women and different age groups, but the similarities were much greater.

Satisfaction with household income and standard of living, negative affect, and social support were strong predictors of life satisfaction in all groups. In addition, positive affect was a significant predictor of life satisfaction in all groups except among emerging adults, whereas unemployment contributed significantly to life satisfaction in all groups, except among older adults. These findings are in line with previous studies that used GWP data and showed that both financial satisfaction and post-material needs were significant predictors of life satisfaction (Ng \& Diener, 2014). Among the post-material needs, only social support was a consistent predictor of life satisfaction in both genders and across age groups, and it supported the crucial role of interpersonal relationships in human wellbeing. Previous studies have also found that social support was a robust predictor of life satisfaction across different periods of life (Siedlecki, Salthouse, Oishi, \& Jeswani, 2014).

Strong associations between life satisfaction and both positive and negative emotions are not surprising, given that they are components of the overarching construct of SWB. Previous studies have shown that positive and negative emotions are among the strongest predictors of life satisfaction (Kööts-Ausmees, Realo, \& Allik, 2012), and some authors (e.g., Davern, Cummins, \& Stokes, 2007) even argue that SWB is primarily an affective construct. It is important to note that negative affect had a somewhat greater unique contribution in predicting life satisfaction than positive affect across both genders and all age groups. These results are not in accordance with Kuppens and colleagues (Kuppens, Realo, \& Diener, 2008), who, in a cross-national study, found that positive emotions were more strongly associated with life satisfaction than negative emotions. However, these differences should be interpreted with caution, because measures of affect and life satisfaction were not the same in our study and the study conducted by Kuppens and colleagues. Positive affect in the present study was assessed using only two indicators (enjoyment and laughter), whereas negative affect was measured using a broader range of experiences (worry, sadness, stress, and anger). This might 
have led to a weaker unique contribution of positive affect in comparison to negative affect in predicting life satisfaction.

Some age- and gender-specific predictors of life satisfaction were observed in the present study. For example, volunteering was positively associated with life satisfaction only among emerging adults (aged 15-24), and perceived freedom and respect only among young adults (aged 25-44), whereas satisfaction with healthcare was a significant predictor of life satisfaction only among middle adults (aged 45-64). In addition, satisfaction with healthcare, donating behaviors, perceived freedom and education were significant predictors of life satisfaction among women but not among men. However, small effects sizes for both age- and genderspecific predictors of life satisfaction suggest that these findings should not be considered robust, and that future studies should comprehensively investigate age and gender differences in life satisfaction determinants. Our findings highlight the importance of taking gender, particular needs, and the specificity of developmental periods into account when investigating life satisfaction, but they also clearly indicate that strong predictors of life satisfaction (such as affective wellbeing, satisfaction with standard of living, social support) had similar effects among men and women and among people of different ages.

It is interesting to note that measures of social capital had only a limited value in predicting life satisfaction. As already noted, volunteering was associated with greater life satisfaction only among emerging adults, whereas donating behaviors were associated with greater life satisfaction among females and all age groups except older adults. On the other hand, corruption and confidence in the government were not significant predictors of life satisfaction in any of the age groups. Similar findings were reported in a study conducted by Jovanović (2016), who found that trust in other people was a significant predictor of life satisfaction among Serbian adults, whereas institutional trust was not. This result is in accordance with previous findings that indicators of social capital and life satisfaction are more closely related in rich countries than in poorer ones (Bjørnskov, 2003; Calvo et al., 2012).

\section{Limitations and conclusions}

The present study has several limitations which should be addressed in future studies. First, we examined the predictive value of a broad range of variables associated with life satisfaction, but a number of important predictors of wellbeing were not included. Future studies should investigate the incremental value of socio-demographic variables, needs satisfaction and measures of social capital over and beyond personality traits, which are among the most robust predictors of wellbeing (e.g., Steel, Schmidt, \& Shultz, 2008). In addition, life events should be included in research on determinants of cognitive wellbeing, as they can have both short- and long-term effects on life satisfaction (Luhmann, Hofmann, Eid, \& Lucas, 2012). Second, the present data did not provide the opportunity to identify relationships between wellbeing and predictors that hold within persons. Therefore, future studies should use longitudinal designs to investigate causal relationships between life satisfaction and its determinants.

Despite these limitations, this study provides pioneering evidence on the state of and major determinants of SWB in Serbia by using a representative sample. Our findings have both theoretical and practical implications. The results of the present study clearly show that the major predictors of life satisfaction identified in previous studies also hold true for Serbia, suggesting that certain processes that underlie wellbeing are common across cultures. We should bear in mind, however, that our results about predictors of life satisfaction in Serbia are 
pioneering, and that data are not yet strong enough to warrant solid conclusions about specific policy implications. Yet, our findings do provide some general policy-relevant suggestions. For example, the results showing that both material (e.g., household income) and sociopsychological factors (e.g., social support, freedom) matter for life satisfaction in Serbia, indicate that policy makers interested in improving wellbeing should not focus exclusively on economic and material processes (e.g., reducing unemployment and increasing wages). Unfortunately, wellbeing surveys are not currently used for policy purposes in Serbia. The accumulation of reliable knowledge and well-confirmed conclusions about wellbeing in Serbia appears essential for initiating public dialogue about the relevance of wellbeing for policy issues. The present study was a preliminary step towards that goal.

\section{Acknowledgements}

This work was supported by the Ministry of Education of the Republic of Korea and the National Research Foundation of Korea (NRF-2017S1A3A2066611).

\section{Authors}

Veljko Jovanović

University of Novi Sad, Serbia

veljko.jovanovic@ff.uns.ac.rs

Mohsen Joshanloo

Keimyung University, South Korea

\section{Publishing Timeline}

Received 7 February 2018

Accepted 29 November 2018

Published 3 April 2018

\section{References}

Arnett, J. J. (2000). Emerging adulthood: A theory of development from the late teens through the twenties. American Psychologist, 55(5), 469-480. https://dx.doi.org/10.1037/0003-066X.55.5.469

Batz, C., \& Tay, L. (2018). Gender differences in subjective well-being. In E. Diener, S. Oishi, \& L. Tay (Eds.), Handbook of well-being. Salt Lake City, UT: DEF.

Beker, K., Gujaničić, R., Rudić Vranić, R., Ćelović, Z., Nešić, R., \& Simonović Veljković, G. (2017). Situation of rural women in Serbia - report.

http://rs.one.un.org/content/dam/unct/serbia/docs/Publications/Situation\%20of\%20rural\%20women \%20in\%20Serbia_ENG_final.pdf

Belgrade Centre for Human Rights. (2017). Human rights in Serbia 2016: Law, practice and international human rights standards. Belgrade, Serbia: The Belgrade Centre for Human Rights.

Bjørnskov, C. (2003). The happy few: Cross-country evidence on social capital and life satisfaction. Kyklos, 56(1), 3-16. https://doi.org/10.1111/1467-6435.00207

Blanchflower, D. G., \& Oswald, A. J. (2008). Is well-being U-shaped over the life cycle? Social Science \& Medicine, 66(8), 1733-1749. https://doi.org/10.1016/j.socscimed.2008.01.030

Busseri, M. A., \& Sadava, S. W. (2011). A review of the tripartite structure of subjective well-being: Implications for conceptualization, operationalization, analysis, and synthesis. Personality and Social Psychology Review, 15(3), 290-314. https://dx.doi.org/10.1177/1088868310391271 
Calvo, R., Zheng, Y., Kumar, S., Olgiati, A., \& Berkman, L. F. (2012). Well-being and social capital on planet Earth: Cross-national evidence from 142 countries. PLoS ONE, 7(8), e42793. https://doi.org/10.1371/journal.pone.0042793

Camfield, L. (2012). Quality of life in developing countries. In K. C. Land, A. C. Michalos, \& M. J. Sirgy (Eds.), Handbook of social indicators and quality of life research (pp. 399-432). Dordrecht, the Netherlands: Springer.

Cantril, H. (1965). Pattern of human concerns. New Brunswick, NJ: Rutgers University Press.

Cheng, T., Powdthavee, N., \& Oswald, A. J. (2017). Longitudinal evidence for a midlife nadir: Result from four data sets. Economic Journal, 127(599), 126-142. https://doi.org/10.1111/ecoj.12256

Center for Liberal-Democratic Studies. (2014). Corruption assessment report: Serbia. Belgrade, Serbia: Author.

Davern, M., Cummins, R. A., \& Stokes, M. (2007). Subjective wellbeing as an affective/cognitive construct. Journal of Happiness Studies, 8(4), 429-449. https://doi.org//10.1007/s10902-007-9066-1

Deaton, A. (2008). Income, health, and well-being around the world: Evidence from the Gallup World Poll. Journal of Economic Perspectives, 22(2), 1-20. https://doi.org/10.1257/jep.22.2.53

De Neve, J.-E., Diener, E., Tay, L., \& Xuereb, C. (2013). The objective benefits of subjective well-being. In J. Helliwell, R. Layard, \& J. Sachs (Eds.), World happiness report 2013 (pp. 54-79). New York, NY: UN Sustainable Development Solutions Network.

Diener, E., \& Chan, M. Y. (2011). Happy people live longer: Subjective well-being contributes to health and longevity. Applied Psychology: Health and Well-Being, 3(1), 1-43. https://doi.org/10.1111/j.17580854.2010.01045.x

Diener, E., Lucas, R. E., \& Oishi, S. (2018). Advances and open questions in the science of subjective wellbeing. Collabra: Psychology, 4(1), 15. http://doi.org/10.1525/collabra.115

Diener, E., Suh, E. M., Lucas, R. E., \& Smith, H. L. (1999). Subjective well-being: Three decades of progress. Psychological Bulletin, 125(2), 276-302. https://doi.org/10.1037/0033-2909.125.2.276

Diener, E., Tay, L., \& Myers, D. G. (2011). The religion paradox: If religion makes people happy, why are so many dropping out? Journal of Personality and Social Psychology, 101(6), 1278-1290. https://doi.org/10.1037/a0024402

Diener, E., \& Ryan, K. (2009). Subjective well-being: A general overview. South African Journal of Psychology, 39(4), 391-406. https://doi.org/10.1177/008124630903900402

Dolan, P., \& Metcalfe, R. (2012). Measuring subjective wellbeing: Recommendations on measures for use by national governments. Journal of Social Policy, 41(2), 409-427. https://doi.org/10.1017/S0047279411000833

Easterlin, R. A. (2001). Income and happiness: Towards a unified theory. The Economic Journal, 111(473), 465-484. https://doi.org/10.1111/1468-0297.00646

Easterlin, R. A. (2013). Happiness, growth and public policy. Economic Inquiry, 51(1), 1-15. https://doi.org/10.1111/j.1465-7295.2012.00505.x

Erikson, E. H. (1968). Identity: Youth, and crisis. New York, NY: Norton.

Eurofound. (2012). Third European Quality of Life Survey - Quality of life in Europe: Impacts of the crisis. Luxembourg: Publications Office of the European Union.

Frey, B. S., \& Stutzer, A. (2002). What can economists learn from happiness research? Journal of Economic Literature, 40(2), 402-435. https://doi.org/10.1257/002205102320161320

Galinha, I., \& Pais-Ribeiro, J. L. (2011). Cognitive, affective and contextual predictors of subjective wellbeing. International Journal of Wellbeing, 2(1), 34-53. https://doi.org/10.5502/ijw.v2i1.3

Gallup, Inc. (2015). State of global well-being: Results of the Gallup-Healthways Global Well-being Index. http://info.healthways.com/hubfs/Well-Being_Index/2014_Data/GallupHealthways_State_of_Global_Well-Being_2014_Country_Rankings.pdf

Health Consumer Powerhouse. (2016). Euro Health Consumer Index 2015 Report. Brussels, Belgium: Author.

Helliwell, J., Layard, R., \& Sachs, J. (2018). World Happiness Report 2018. New York, NY: Sustainable Development Solutions Network. 
Henrich, J., Heine, S. J., \& Norenzayan, A. (2010). The weirdest people in the world? Behavioral and Brain Sciences, 33(2-3), 61-83. https://doi.org/10.1017/S0140525X0999152X

Hofstede, G. H., Hofstede, G. J., \& Minkov, M. (2010). Cultures and organizations: Software of the mind (3rd ed.). New York, NY: McGraw-Hill.

Howell, R. T., \& Howell, C. J. (2008). The relation of economic status to subjective well-being in developing countries: A meta-analysis. Psychological Bulletin, 134(4), 536-560. https://doi.org/10.1037/0033-2909.134.4.536

Jovanović, V. (2016). Trust and subjective well-being: The case of Serbia. Personality and Individual Differences, 98, 284-288. https://doi.org/10.1016/j.paid.2016.04.061

Kahneman, D., \& Deaton, A. (2010). High income improves evaluation of life but not emotional wellbeing. Proceedings of the National Academy of Sciences of the United States of America, 107(38), 1648916493. https://doi.org/10.1073/pnas.1011492107

Kööts-Ausmees, L., Realo, A., \& Allik, J. (2012). The relationship between life satisfaction and emotional experience in 21 European countries. Journal of Cross-Cultural Psychology, 44(2), $223-244$. https://doi.org/10.1177/0022022112451054

Krstić, G. (2016). Why income inequality is so high in Serbia: Empirical evidence and a measurement of the key factors. Economic Annals, 61(220), 23-46. https://doi.org/10.2298/EKA1610023K

Kuppens, P., Realo, A., \& Diener, E. (2008). The role of positive and negative emotions in life satisfaction judgment across nations. Journal of Personality and Social Psychology, 95(1), 66-75. https://doi.org/10.1037/0022-3514.95.1.66

Legatum Institute. (2017). The $2017 \quad$ Legatum Prosperity Index. www.prosperity.com/download_file/view/3479

Lomas, T. (2015). Positive cross-cultural psychology: Exploring similarity and difference in constructions and experiences of wellbeing. International Journal of Wellbeing, 5(4), 60-77. https://doi.org/10.5502/ijw.v5i4.437

Lucas, R. E., \& Diener, E. (2015). Personality and subjective well-being: Current issues and controversies. In M. Mikulincer, P. R. Shaver, M. L. Cooper, \& R. J. Larsen (Eds.), APA handbook of personality and social psychology: Vol. 4. Personality processes and individual differences (pp. 577-599). Washington, DC: American Psychological Association.

Luhmann, M., Hofmann, W., Eid, M., \& Lucas, R. E. (2012). Subjective well-being and adaptation to life events: A meta-analysis. Journal of Personality and Social Psychology, 102(1), 592-615. https://doi.org/10.1037/a0025948

Ng, W., \& Diener, E. (2014). What matters to the rich and the poor? Subjective well-being, financial satisfaction, and post-materialistic needs across the world. Journal of Personality and Social Psychology, 107(2), 326-338. https://doi.org/10.1037/a0036856

Ngoo, Y. T., Tey, N. P., \& Tan, E. C. (2015). Determinants of life satisfaction in Asia. Social Indicators Research, 124(1), 141-156. https://doi.org/10.1007/s11205-014-0772-x

Oishi, S., \& Diener, E. (2014). Can and should happiness be a policy goal? Policy Insights from the Behavioral and Brain Sciences, 1(1), 195-203. https://doi.org/10.1177/2372732214548427

Rašević, M. (2010). On ageing and old age in Serbia. Zbornik Matice srpske za društvene nauke [Matica Srpska Social Sciences Quarterly], 131, 199-209.

Rukumnuaykit, P., \& Pholphirul, P. (2016). Happiness from social capital: An investigation from micro data in rural Thailand. Community Development, 47(4), 562-573. https://doi.org/10.1080/15575330.2016.1206584

Sacks, D. W., Stevenson, B., \& Wolfers, J. (2012). The new stylized facts about income and subjective wellbeing. Emotion, 12(6), 1181-1187. https://doi.org/10.1037/a0029873

Sevo, G., Davidovic, M., Erceg, P., Despotovic, N., Milosevic, D. P., \& Tasic, M. (2015). On aging and aged care in Serbia. Journal of Cross-cultural Gerontology, 30, 217-231. https://doi.org/10.1007/s10823015-9261-1

Shucksmith, M., Cameron, S., Merridew, T., \& Pichler, F. (2009). Urban-rural differences in quality of life across the European Union. Regional Studies, 43(10), 1275-1289. https://doi.org/10.1080/00343400802378750 
Siedlecki, K. L., Salthouse, T. A., Oishi, S., \& Jeswani, S. (2014). The relationship between social support and subjective well-being across age. Social Indicators Research, 117(2), 561-576. https://doi.org/10.1007/s11205-013-0361-4

Šobot, A. (2014). Economic activity of middle-aged women in Serbia as relevant gender equality issue. Zbornik Matice srpske za društvene nauke [Matica Srpska Social Sciences Quarterly], 148, 499-510. https://doi.org/10.2298/ZMSDN1448499S

Stavrova, O., Fetchenhauer, D., \& Schlösser, T. (2013). Why are religious people happy? The effect of the social norm of religiosity across countries. Social Science Research, 42(1), 90-105. https://doi.org/10.1016/j.ssresearch.2012.07.002

Steel, P., Schmidt, J., \& Shultz, J. (2008). Refining the relationship between personality and subjective well-being. Psychological Bulletin, 134(1), 138-161. https://doi.org/10.1037/0033-2909.134.1.138

Steger, M. F., Oishi, S., \& Kashdan, T. B. (2009). Meaning in life across the life span: Levels and correlates of meaning in life from emerging adulthood to older adulthood. The Journal of Positive Psychology, 4(1), 43-52. https://doi.org/10.1080/17439760802303127

Steptoe, A., Deaton, A., \& Stone, A. A. (2015). Subjective wellbeing, health, and ageing. Lancet, 385(9968), 640-648. https://doi.org/10.1016/S0140-6736(13)61489-0

The World Bank Group. (2015). Republic of Serbia: Country Partnership Framework, 2016-2020 (Report No. 100464-YF). Washington, DC: Author.

Tov, W., \& Diener, E. (2007). Culture and subjective-well-being. In S. Kitayama \& D. Cohen (Eds.), Handbook of cultural psychology (pp. 691-713). New York, NY: Guilford.

Veenhoven, R. (2015). Social conditions for human happiness. International Journal of Psychology, 5(5), 379391. https://doi.org/10.1002/ijop.12161

Verbakel, E. (2012). Subjective well-being by partnership status and its dependence on the normative climate. European Journal of Population / Revue Europenne de Demographie, 28(2), 205-232. https://doi.org/10.1007/s10680-012-9257-2

Winkelmann, R. (2014). Unemployment and happiness. IZA World of Labor, 94, 1-10.

Zhang, W., Braun, K. L., \& Wu, Y. Y. (2017). The educational, racial and gender crossovers in life satisfaction: Findings from the Longitudinal Health and Retirement Study. Archives of Gerontology and Geriatrics, 73, 60-68. https://doi.org/10.1016/j.archger.2017.07.014 